\title{
Extension of Log-Spiral-Rankine (LSR) Model for Earth Pressure Analysis to a Sloping Backfill
}

\author{
Abiodun Ismail Lawal, Shi-Yu Xu \\ City University of Hong Kong \\ Kowloon, Hong Kong \\ ailawal2-c@my.cityu.edu.hk; shiyuxu@cityu.edu.hk
}

\section{Extended Abstract}

Retaining walls are common geotechnical engineering structures constructed to maintain the stability of soil between two different ground levels. A large number of experimental, analytical and numerical studies have been carried out to estimate the magnitudes of earth thrusts acting on the walls (see, for example, [1], [2], [3] among others). Nevertheless, many of the existing methods oversimplified the problem (by, for instance, ignoring soil cohesion, assuming a linear failure surface, and/or presuming an unrealistic stress distribution in the backfill), and thus, can be applied only to limited scenarios. A recently published analytical model, known as the Log-Spiral-Rankine (LSR) method [4, 6], dropped the aforementioned simplifications and outlined a more rigorous procedure which has been verified [5] to produce improved predictions over most of the existing analytical models. The LSR method, however, is currently limited to the scenario with a vertical wall retaining a levelled ground. The study presented here aims to generalize the LSR model to accommodate backfill and/or wall inclinations.

The LSR method adopts the limit equilibrium concept to compute the critical earth thrust which mobilizes the backfill soil along a composite logarithmic-spiral-shaped sliding surface. To extend the LRS method to non-vertical walls retaining sloping grounds, the stress states and the corresponding angles of inclination of the failure surface at the two boundaries of the mobilized soil mass are first re-examined. Then, the procedure as outlined in the LSR method is followed to calculate the critical earth thrust. As at the moment experimental data derived under the targeted retaining wall and ground surface configurations is scarce, the numerical results obtained from finite element simulation (using ABAQUS) are used to verify the analytical results yielded by the extended LSR method proposed in this study.

The failure geometry predicted by the proposed method converges to that predicted by the LSR method when the backfill inclination and the wall inclination angles are set to zero. It also shows a good agreement with that obtained from the finite element simulation.

The results of the analysis reveal that an increase in the angle of inclination of the backfill will cause an increase in the earth thrusts. As for the wall, an increase in the inclination angle of the wall will result in an increase in the active earth thrust whereas a decrease in the passive earth thrust.

The results also show that the point of application of the resultant earth thrust vary significantly with the angle of inclination of the backfill and that of the wall.

\section{References}

[1] C. A. Coulomb, "Essai sur une application des regles des maximis et minimis a quelques problemes de statique relatifs a l'architecture," Memoires de l'Academie Royale pres Divers Savants, vol. 7, 1778.

[2] W. Rankine, "On the stability of loose earth," Philosophical Transactions of the Royal Society of London, vol. 147, 1857.

[3] K. Terzaghi, Theoretical soil mechanics. New York: Wiley, 1943.

[4] A. Shamsabadi, S-Y. Xu, and E. Taciroglu, "A generalized log-spiral-Rankine limit equilibrium model for seismic earth pressure analysis,” S. Dyn Earthq Eng, vol. 49, pp. 197-209, 2013.

[5] A. Shamsabadi, M. Ashour and G. Norris, "Bridge abutment nonlinear force- displacement-capacity prediction for seismic design," J. Geotech and Geoenviron Engin., vol. 131, no. 2, pp. 151-161 ASCE, 2005. 
[6] S-Y. Xu, A. Shamsabadi, E. Tacirogl, "Evaluation of active and passive seismic earth pressures considering internal friction and cohesion," S. Dyn. and Earthq. Engin., vol. 70, pp. 30-47, 2015. 